\section{Mental health functioning among men who use the Internet specifically to find partners for unprotected sex}

\author{
Hugh Klein \\ Kensington Research Institute, Silver \\ Spring, MD, USA
}

\section{Abstract}

Previous studies have shown a link between mental health functioning and involvement in HIV risk practices. The present research examines how well one specific group of men who have sex with other men (MSM) fare in terms of their mental health functioning, and then focuses on how mental health functioning relates to HIV risk practices in this population. The study was based on a national random sample of 332 MSM who use the Internet to seek men with whom they can engage in unprotected sex. Data collection was conducted via telephone interviews between January 2008 and May 2009. Depression is more common among men in this population than in the adult male population-at-large. All other measures of mental health functioning that were examined (self-esteem, impulsivity, current life satisfaction, optimism about the future) indicated low rates of mental health problem. Contrary to expectations, in nearly all instances, mental health functioning was not related to HIV risk practices.

More work needs to be done to understand the causes of depression among these men, and to assess how, if at all, depression relates to risk practices in this population. These findings suggest that factors other than mental health problems must be considered if one wishes to understand HIV risk taking in this population.

\section{Introduction}

To date, approximately one million Americans have been diagnosed with AIDS and estimates suggest that nearly one-quarter million more are living with HIV that has not developed into AIDS. ${ }^{1}$ Men who have sex with other men (MSM) comprise the largest proportion of these individuals, accounting for $63 \%$ of all reported cases of AIDS with a known source of transmission and 59\% of all HIV-positive persons who believed that they knew how they became HIV-infected.1 Despite the so-called changing face of AIDS in America - that is, changes in the proportions of persons of vari- ous population subgroups that are more/less affected by HIV now than in previous years these percentages for MSM remained stable throughout most of the past ten years, with recent evidence suggesting that these proportions currently may be on the rise. 1,2

In light of this, numerous studies have been conducted to identify why, approximately 30 years into the HIV/AIDS epidemic, so many men continue to place themselves at risk for contracting HIV. Many factors have been identified, including the belief that engaging in unprotected sex is an expression of individual choice, 3,4 the belief that engaging in unprotected sex is an expression of masculinity, ${ }^{5-7}$ the perception that AIDS antiretroviral drugs have made HIV/AIDS less of a health concern now than in prior years, 8,9 a fear of being rejected sexually by partners who dislike condoms, ${ }^{9}$ the belief that sex is more pleasurable when condoms are not used,4,10,11 feeling burned out by worrying about becoming HIVinfected, 8,10 and feeling a greater sense of emotional connectedness to sexual partners with whom one had unprotected rather than protected sex.11,12

In addition to the preceding, in recent years, there has been growing interest in examining the role that mental health factors play in men's HIV-related risk-taking behaviors. Most of the published studies in this area have examined the relationship of self-esteem, depression, impulsivity, or coping to risk taking. Their findings are summarized below.

When it comes to self-esteem and HIV risk taking, the usual hypothesis, which is supported by most of the studies published on the topic, is that lower self-esteem will correspond to greater involvement in risk. The idea here is that people who think poorly of themselves are less inclined and/or less capable of taking good, proper care of themselves, including a diminished ability and/or willingness to make sure that they stay safe from HIV. In a study of barebacking men (i.e., those who engage in intentional unprotected anal intercourse), for example, Adam et al..$^{13}$ reported that lower selfesteem was associated with less condom use. Similarly, in a study of rural MSM, Preston et al. ${ }^{14}$ found that lower self-esteem was related to greater sexual risk taking. Moskowitz and Seal reported that, 15 among HIV-positive MSM but not among their HIV-negative counterparts, HIV serostatus disclosure was greater among men with higher levels of self-esteem. In a study of young MSM residing in New York City, lower self-esteem was associated with more unprotected anal sex, more sex partners, and a larger number of sexual encounters. ${ }^{16}$ In another study of young men (specifically, 15-24 year-old HIV-positive males), lower self-esteem was linked with greater involvement in risky sexual practices such as not using condoms during sex, failing to inform sex partners that
Correspondence: Hugh Klein, Kensington Research Institute, 401 Schuyler Road, Silver Spring, Maryland 20910, USA.

Tel. +1.301.5888875

E-mail: hughk@aol.com, hughkhughk@yahoo. com

Key words: men who have sex with men, Internet, mental health, HIV risk practices, self-esteem, depression, impulsivity, life satisfaction, optimism.

Conflict of interests: the author declares no potential conflict of interests.

Acknowledgments: the author wishes to acknowledge, with gratitude, the contributions made by Thomas P. Lambing to this study's data collection and data entry/cleaning efforts. The author also thanks David Tilley for providing helpful comments on an earlier draft of this manuscript.

Funding: this research (officially entitled Drug Use and HIV Risk Practices Sought by Men Who Have Sex with Other Men, and Who Use Internet Websites to Identify Potential Sexual Partners) was supported by a grant (5R24DA019805) from the National Institute on Drug Abuse.

Received for publication: 21 July 2011. Accepted for publication: 15 March 2013.

This work is licensed under a Creative Commons Attribution NonCommercial 3.0 License (CC BYNC 3.0).

(C) Copyright H. Klein., 2013

Licensee PAGEPress, Italy

Mental Illness 2013; 5:e6

doi:10.4081/mi.2013.e6

one was HIV-positive, and having a larger number of sex partners. ${ }^{17}$ Based on their research with HIV-positive methamphetamineusing MSM, Semple and colleagues reported that lower self-esteem was linked with greater sexual compulsivity.18,19 This is of especial concern because methamphetamine use is common among gay and bisexual men,20,21 and it has been shown in many studies to be an independent risk factor for HIV transmission. ${ }^{22,23}$ One of the few exceptions reported in the esteem-and-HIV-risk literature was noted by Reilly and Woo, ${ }^{24}$ who reported that selfesteem was not associated with having (un)protected sex in their sample of men living with HIV. With regard to depression and HIV risk taking, the usual underlying assumption is that people who are depressed turn to various types of substance use/abuse and sexual risk practices as forms of cognitive escapism to help them cope with their negative emotional state. ${ }^{25}$ Speaking from a clinical psychology perspective, Shernoff noted that depression often leads gay men to be hyperac- 
tive sexually and to engage in unprotected sex. ${ }^{26}$ Most, but not all,24,27 of the published studies on this topic have shown that depression is linked with greater involvement in risk practices among MSM. For example, in their sample of African American MSM, Mimiaga et $a l .28$ reported that experiencing more clinically-significant symptoms of depression was associated with more stimulant use during sex. Other work published by members of that same research team showed that depression was associated with a nearly tripled risk of having unprotected anal sex with a serodiscordant partner, as well as an eight-fold increase in the likelihood of recently having had a sexually transmitted infection.29,30 Additionally, MSM who were trying to reduce their risk for HIV by engaging in specific low-risk activities were less likely to experience depression than men who were not engaging in these specific risk-reduction practices. ${ }^{30}$ In a sample of HIVpositive MSM, Ross, Rosser, and Neumaier found that internalized homophobia was linked with greater depression, and that internalized homophobia was linked with greater involvement in unprotected anal intercourse with serodiscordant sex partners. ${ }^{79}$ One study of younger MSM found that these persons were more depressed than their older counterparts and more involved in risky practices. ${ }^{31}$ This led the authors to conclude that depressive symptoms ... may contribute to greater rates of substance use and other risk-taking behaviors among YMSM (p. 817). Another study of younger MSM (23-29 year-olds) in the Seattle area reported that greater depression was associated with having three or more sex partners but none of the other risk measures examined. ${ }^{32}$ In a study of MSM aged 40-70, men attributed their own HIV risk taking to feelings of depression as well as to other factors, such as inability to maintain erections when using condoms, impending mortality, and trading off safer sex. ${ }^{33}$ Other studies reporting on a link between greater depression and greater involvement in various types of HIV risk have included Mimiaga and colleagues' multi-site study of MSM, ${ }^{34}$ Parsons and colleagues' bicoastal study of HIV-positive MSM, ${ }^{35}$ Bousman and colleagues' research on HIV-positive methamphetamine-using MSM, ${ }^{36}$ Bancroft and colleagues' research with gay men, 37 Alvy and colleagues' national study of men engaging in drug (ab)use and unprotected sex, ${ }^{38}$ Semple, Patterson, and Grant's work with HIV-positive gay men who had sex with seronegative or serostatus-unknown sex partners, ${ }^{18}$ Walch and Rudolph's research on bisexual men, ${ }^{39}$ and Parsons and Halkitis' examination of men frequenting commercial sex establishments, such as bathhouses and sex clubs. ${ }^{25}$

Research focusing on the nexus of impulsivity and HIV risk taking has been conducted with the assumption that people who are impulsive are less apt to ask their sex partners about their HIV testing history, less apt to try to negotiate sexual safety with new partners, and more likely to make spur-of-the-moment sexual decisions that place them at risk for contracting or transmitting HIV, when compared to their less-impulsive peers. Research on this subject has been limited, but generally consistent with these assumptions. For example, in their study of HIV-positive methamphetamineusing MSM, Semple and colleagues found that greater impulsivity was related to more unprotected sex.19,40 In their sample, there was an interaction between impulsivity and the amount of methamphetamine use men reported, suggesting that risk was greatest among highly-impulsive, more drug-involved MSM. Based on their work with midwestern MSM aged 13-21, Dudley et al.41 found that greater impulsiveness in decision making was associated with having unprotected sex more frequently. Semple, Patterson, and Grant found that there was an association between greater impulsivity and having unprotected anal sex in their sample of HIV-positive gay men who had sex with seronegative or serostatus-unknown sex partners. ${ }^{18}$ One study that did not find a relationship between impulsivity and risk taking was published by McCoul and Haslam. ${ }^{42}$

With regard to coping and HIV risk involvement, it is important to bear in mind that coping may be undertaken in healthy or adaptive ways (e.g., exercising to reduce stress, speaking to a mental health professional, confiding in a trusted friend, engaging in favorite hobbies) or in ways that are unhealthy or maladaptive (e.g., using drugs, avoiding dealing with a person or a problem, drinking to excess). The latter types of coping practices are hypothesized to be related to heightened risk for HIV transmission and, indeed, published reports on this subject support this hypothesis. For example, in a study of HIV-negative gay men in New York City, disengagement coping was related to having unprotected anal intercourse. ${ }^{43}$ In their study of HIV-positive men attending gay community events, Kelly et al.44 found that men who barebacked engaged in more avoidant coping than those who were not barebacking. Martin, Pryce, and Leeper found that, ${ }^{45}$ among MSM, the use of avoidance coping strategies was associated with more unprotected anal intercourse. Semple, Patterson, and Grant found that there was an association between greater avoidant coping and having unprotected anal sex in their sample of HIV-positive gay men who had sex with seronegative or serostatus-unknown sex partners. ${ }^{18}$ Based on their work with HIVpositive males aged 15-24, Stein and colleagues found that negative coping styles were associated with an increased risk for the sexual transmission of HIV. ${ }^{17}$ Based on a four-site study of HIV-positive MSM, Morin and col- leagues concluded that low coping self-efficacy was related to an elevated HIV transmission risk with casual sex partners. ${ }^{46}$

In summary, as a general rule, studies focusing on the relationship of mental health functioning to HIV risk taking operate from a premise that risk taking is a manifestation of some type of psychological or psychosocial need, or the result of some type of mental health problem, for which men seek fulfillment or relief by becoming involved in behaviors that place them at risk for contracting HIV. The extent to which this is a valid assumption, though, has been subjected to little empirical testing. The present study examines the issue of mental health functioning and HIV risk involvement in one specific population of risk-seeking men, and focuses on the following research questions: i) How well do these men fare with regard to their mental health functioning? How prevalent are problems in various aspects of their mental health? ii) How, if at all, do problems with mental health functioning correspond to involvement in various types of HIV risk practices among members of this population? The article concludes by discussing the HIV prevention- and intervention-related implications of the findings.

\section{Materials and Methods}

\section{Procedures}

The data reported in this paper come from The Bareback Project, a National Institute on Drug Abuse-funded study of men who use the Internet specifically to find other men with whom they can engage in unprotected sex. The data were collected between January 2008 and May 2009. A total of 332 men were recruited from 16 different websites. Some of the sites catered exclusively to unprotected sex (e.g., Bareback.com, RawLoads.com) and some of them did not but made it possible for site users to identify which persons were looking for unprotected sex (e.g., Men4SexNow.com, Squirt.org). A nationwide random sample of men was derived, with random selection being based on a combination of the first letter of the person's online username, his race/ethnicity (as listed in his profile), and the day of recruitment. Recruitment efforts were undertaken seven days a week, during all hours of the day and nighttime, variable from week to week throughout the duration of the project. This was done to maximize the representativeness of the final research sample, in recognition of the fact that different people use the Internet at different times.

Depending upon the website involved, men were approached initially either via instant message or email (much more commonly via 
email). A brief overview of the study was provided as part of the initial approach and informed consent-related procedures, and all men were given the opportunity to ask questions about the study before deciding whether or not to participate. A website link to the project's online home page was also made available, to provide men with additional information about the project and to help them feel secure in the legitimacy of the research endeavor. Interviews were conducted during all hours of the day and nighttime, seven days a week, based on interviewer availability and participants' preferences, to maximize convenience to the participants.

Participation in the study entailed the completion of a one-time, confidential telephone interview covering a wide array of topics. The questionnaire was developed specifically for use in The Bareback Project, with many parts of the interview derived from standardized scales previously used and validated by other researchers. The interview covered such subjects as: degree of outness, perceived discrimination based on sexual orientation, general health practices, HIV testing history and serostatus, sexual practices (protected and unprotected) with partners met online and offline, risk-related preferences, risk-related hypotheticals, substance use, drug-related problems, Internet usage, psychological and psychosocial functioning, childhood maltreatment experiences, HIV/AIDS knowledge, and some basic demographic information. Interviews lasted an average of 69 min (median $=63, \mathrm{SD}=20.1$, range: $30-210$ ). Men who completed the interview were compensated $\$ 35$ for their time. Prior to implementation in the field, the research protocol was approved by the institutional review boards at Morgan State University, where the principal investigator and one of the research assistants were affiliated, and George Mason University, where the other research assistant was located.

\section{Measures used}

Standardized scales developed and validated by other researchers were used to assess study participants' mental health, in conjunction with Research Questions \#1 and \#2. Selfesteem was assessed via the use of Rosenberg's well-known scale. ${ }^{47}$ Responses to the ten items comprising the scale were scored in five-point Likert fashion (ranging from strongly disagree to strongly agree) and the scale itself was found to be reliable (Cronbach's alpha: 0.89). Depression was measured via the Center for Epidemiologic Studies Depression (CES-D) scale, ${ }^{48}$ which asks respondents to indicate the number of days they experienced each of 20 symptoms of depression. Reliability for this scale was excellent (Cronbach's alpha: 0.93), and previous studies have shown the CES-D to be related quite closely to diagnoses of depression made by psychiatric professionals as well as to the diagnostic criteria established in the DSMIV. 49,50 Fifteen items comprising the Barratt Impulsiveness Scale were used to assess impulsivity. ${ }^{51}$ Responses to these items were given in five-point Likert fashion (ranging from strongly disagree to strongly agree) and the scale was reliable (Cronbach's alpha: 0.76). The same response options were offered for the five items comprising the current life satisfaction scale and the six items comprising the optimism about the future scale, both of which were found to be reliable (Cronbach's alphas: 0.83 and 0.78 , respectively). The current life satisfaction items were adapted from the Satisfaction with Life scale, 52 and the optimism about the future measures came from the Life Orientation Test-Revised. ${ }^{53}$

Based on men's responses to these items, a separate dichotomous measure was constructed to determine whether or not they were suffering from problems, on any of these five mental health measures. For this dichotomous measure, men were considered to be suffering if they had an average score lower than a 2.5 (on a 1-5 scale) on the self-esteem scale, lower than a 2.5 (on a 1-5 scale) on the current life satisfaction scale, lower than a 2.5 (on a 1-5 scale) on the scale measuring optimism about the future, greater than a 3.5 (on a 1-5 scale) on the impulsivity scale, and/or in the scoring range generally considered to be indicative of clinically depressive symptomatology on the CES-D. 54

Ten specific measures of HIV risk involvement were examined in conjunction with Research Question \#2. First, men were asked about the number of different men with whom they had had any kind of sex during the past 30 days (continuous measure). Men who initially responded don't know were instructed: Please take a moment and think about it, and give me a number that you know is definitely safe that is, the number of men with whom you have had any kind of sex that you know. It is definitely no less than $|x|$ persons. For example, you definitely had sex with no fewer than 3 men, or no fewer than 30 men, or no fewer than 300 men, and so forth. In this manner, self-reports of the number of sex partners range from accurate to conservative estimates.

For insertive oral sex, receptive oral sex, insertive anal sex, receptive anal sex, and insertive vaginal sex, separate questions were asked about the number of times engaging in each behavior during the previous 30 days (continuous), the number of those times in which the insertive partner wore a condom (continuous), and the number of those times that the receptive partner received ejaculatory fluid directly inside of the mouth or anus (continuous). This information was used to create measures of the proportion of all sex acts involving the use of a condom (continuous), the proportion of anal sex acts involving the use of a condom (continuous), the proportion of all sex acts involving internal ejaculation (continuous), and the proportion of anal sex acts involving internal ejaculation (continuous).

Men's practices of multiple-partner sex were ascertained by asking How many times have you had any kind of sex in a three-way arrangement, where you and your partner had one other man join you for sex? and How many times have you had any kind of sex involving more than a total of three people - what some people call group sex or orgies? For analytical purposes in the present paper, responses to these items were summed to form a continuous measure indicating the number of times men recently engaged in multiple-partner sex. To learn about men's anonymous sex practices, men were asked: Some people like to have anonymous sex - that is, sex with persons they know nothing about - and some people do not like to do this. Do you like having anonymous sex? (yes/no) and then How many times during the past 30 days have you had anonymous sex of any kind with someone? (continuous)

Drug use behaviors were inquired about in a separate section of the questionnaire. There, men were asked about the number of days of use during the preceding 30 days (continuous), the number of times using on a typical day of use during the past 30 days (continuous), and the number of times using shortly before having sex with someone or while having sex with someone (continuous). These questions were asked separately for alcohol, marijuana, powdered cocaine, crack cocaine, heroin or other opiates, hallucinogens, ecstasy, club drugs other than ecstasy (e.g., ketamine/Special K, GHB, etc.), methamphetamine, Viagra or the equivalent (excluded from the present paper's analysis of illegal drug use), and sedatives or depressant drugs that were not prescribed by a physician. Additionally, men were asked about their past30-days experiences with 14 types of substance abuse problems (each asked in yes/no format), including needing more of a drug in order to get the same effect previously experienced, having problems with family members as a result of one's own substance use/abuse, being unsuccessful in one's efforts to quit or curtail one's own drug intake, experiencing withdrawal symptoms when unable to get alcohol or another drug to use, and so forth.

\section{Analysis}

Research Question \#1, pertaining to the prevalence of mental health problems among study participants, was examined via descriptive data. Research Question \#2, addressing the relationship of mental health functioning and involvement in HIV risk behaviors, was 
examined by computing correlation coefficients (Pearson's $r$ ) for all of the HIV risk measures and the five mental health functioning items. Because correlation coefficients were computed for each risk practice as planned analyses, a Bonferroni correction was used to determine levels of statistical significance. This changed the standard $\mathrm{P}<0.05$ requirement for deeming a finding to be statistically significant to using $\mathrm{P}<0.01$ as the required threshold for considering a finding to be statistically significant. In the final comparison of people who were versus those who were not found to be suffering from some type of mental health problem, Student's $t$ tests were used to compare risk behavior practices because the independent variable was dichotomous and the outcome measures were continuous in nature.

\section{Results \\ Sample characteristics}

In total, 332 men participated in the study. They ranged in age from 18 to 72 (mean: 43.7, $\mathrm{SD}=11.2$, median: 43.2). Racially, the sample is a fairly close approximation of the American population, with $74.1 \%$ being Caucasian, $9.0 \%$ each being African American and Latino, 5.1\% self-identifying as biracial or multiracial, $2.4 \%$ being Asian, and $0.3 \%$ being Native American. The large majority of the men (89.5\%) considered themselves to be gay and almost all of the rest $(10.2 \%)$ said they were bisexual. Most of the men in the study (73.9\%) said that they were single, or not involved in any type of romantic or marital-type relationship. On balance, men participating in The Bareback Project were fairly well-educated. About 1 man in 7 (14.5\%) had completed no more than high school; $34.3 \%$ had some college experience without earning a college degree; $28.9 \%$ had a bachelor's degree; and $22.3 \%$ were educated beyond the bachelor's level. Slightly more than one-half of the men (59.0\%) reported being HIV-positive; most of the rest (38.6\%) were HIV-negative.

\section{Mental health functioning}

As Table 1 demonstrates, poor mental health functioning was atypical of men who participated in The Bareback Project. Very few (3.0\%) were characterized by low self-esteem (mean score less than 2.5 on the 1-5 scale) and most (80.3\%) were high in self-esteem (mean score greater than 3.5). Likewise, very few of the men $(4.9 \%)$ had a pessimistic outlook regarding the future, whereas most (64.8\%) were optimistic about what the future holds in store for them. Similarly, very few of the study participants (3.0\%) scored high on impulsivity, with the remaining men being relatively evenly divided between those who were low on impulsivity and those who were average on this dimension. Somewhat more problematic were men's levels of satisfaction with their current lives, with $19.1 \%$ of them scoring low on life satisfaction and $45.7 \%$ of them scoring high on this dimension. Slightly more than one-half of the men who took part in this study (52.3\%) were not suffering in any consequential way from depression. Subclinical levels of depression were reported by $21.0 \%$ of the study participants and levels of symptoms indicative of clinical depression were reported by $27.6 \%$ of the study participants. When problems with any of these five dimensions were combined into a single dichotomous measure, the results indicated that approximately one-third (33.6\%) of the men were suffering from some combination of low self-esteem, low level of current life satisfaction, low level of optimism about the future, high level of impulsivity, and/or high level of depressive symptomatology.

\section{Mental health functioning and risk involvement}

Table 2 presents the findings for the analyses examining the relationship of mental health functioning to involvement in specific HIV risk practices. For the large majority of the analyses undertaken, there was no association between mental health functioning and risk involvement. The most noteworthy exceptions were found for the number of recent drug problems experienced [which was found to be related to lower self-esteem $(\mathrm{r}=-0.23$, $\mathrm{P}<0.001)$, greater impulsivity $\quad(\mathrm{r}=0.29$, $\mathrm{P}<0.001)$, greater depression $(\mathrm{r}=0.25$,

$\mathrm{P}<0.001$ ), and lower levels of current life satisfaction $(\mathrm{r}=-0.16, \mathrm{P}=0.017)$ and the number of recent sex partners (which was found to be associated with higher self-esteem $(\mathrm{r}=0.16$, $\mathrm{P}=0.017$ ), higher levels of current life satisfaction ( $\mathrm{r}=0.15, \mathrm{P}=0.041)$, and greater optimism about the future $(\mathrm{r}=0.16, \mathrm{P}=0.016)]$.

When the dichotomous overall measure comparing men who did and men who did not suffer from any problems with depression, impulsivity, low self-esteem, low life satisfaction, or low optimism about the future was used to examine HIV risk involvement, no significant differences were found between the groups with regard to their involvement in unprotected sex, their involvement in unprotected anal sex, their involvement in sex involving internal ejaculation, their involvement in anal sex involving internal ejaculation, the number of recent sex partners, their overall amount of illegal drug use, the number of times they had sex while under the influence of alcohol and/or other drugs, the number of times they had anonymous sex, or the number of times they had multiple-partner sex. Only one measure-number of recent drug prob-

Table 1. Mental health functioning among study participants.

Low High Average

\begin{tabular}{lccc} 
Self-esteem & 3.0 & 80.3 & 16.7 \\
Depression & 52.3 & 26.7 & 21.0 \\
\hline Impulsivity & 53.3 & 3.0 & 43.6 \\
Optimism about the future & 4.9 & 64.8 & 32.4 \\
\hline Current life satisfaction & 19.1 & 45.7 & 35.2 \\
\hline
\end{tabular}

Table 2. Mental health functioning and involvement in HIV risk practices.

\begin{tabular}{|c|c|c|c|c|c|}
\hline & ff-esteem & Depression & Impulsivity & Optimism & $\begin{array}{l}\text { Life } \\
\text { satisfaction }\end{array}$ \\
\hline Proportion of protected sex (overall) & 0.07 & -0.07 & -0.07 & 0.07 & 0.01 \\
\hline Proportion of protected anal sex & 0.07 & -0.05 & -0.09 & 0.04 & 0.00 \\
\hline $\begin{array}{l}\text { Proportion of sex involving } \\
\text { internal ejaculation }\end{array}$ & -0.10 & 0.08 & 0.07 & -0.05 & -0.09 \\
\hline $\begin{array}{l}\text { Proportion of anal sex involving } \\
\text { internal ejaculation }\end{array}$ & -0.09 & 0.07 & 0.13 & -0.06 & -0.03 \\
\hline Number of recent sex partners & $0.16^{*}$ & -0.06 & -0.06 & $0.15^{*}$ & $0.16^{*}$ \\
\hline Total amount of recent illegal drug use & 0.11 & -0.04 & 0.07 & 0.07 & $0.13^{\circ}$ \\
\hline $\begin{array}{l}\text { Number of recent drug problems } \\
\text { experienced }\end{array}$ & $-0.23^{* *}$ & $0.25^{* * *}$ & $0.29 * * *$ & $-0.16^{*}$ & -0.11 \\
\hline $\begin{array}{l}\text { Number of times recently having } \\
\text { anonymous sex }\end{array}$ & 0.00 & 0.04 & -0.11 & 0.07 & 0.08 \\
\hline $\begin{array}{l}\text { Number of times recently having } \\
\text { sex while high }\end{array}$ & 0.04 & 0.03 & $0.18^{* *}$ & 0.00 & 0.13 \\
\hline $\begin{array}{l}\text { Number of times having } \\
\text { multiple-partner sex }\end{array}$ & -0.01 & 0.05 & -0.03 & 0.04 & 0.04 \\
\hline
\end{tabular}


lems experienced-differed for these two groups, with the people experiencing some type of mental health problem reporting twice as many drug problems as their counterparts who were faring adequately in terms of their mental health (1.1 versus 0.5 problems, $\mathrm{t}=3.79$, $\mathrm{P}<0.001$ )

\section{Discussion and Conclusions}

Before discussing the main findings obtained in this research, the author wishes to acknowledge three potential limitations of this research. First, the data in this study are based on uncorroborated self-reports. Therefore, it is unknown whether participants underreported or over-reported their involvement in risky behaviors. The self-reported data probably can be trusted, however, as noted by other authors of previous studies with similar populations. ${ }^{55}$ This is particularly relevant for self-reported measures that involve relatively small occurrences (e.g., number of times having a particular kind of sex during the previous 30 days), which characterize the substantial majority of the data collected in this study. 56 Other researchers have also commented favorably on the reliability of self-reported information in their studies regarding topics such as condom use. 57

A second potential limitation is the possibility of recall bias. For most of the measures used, respondents were asked about their beliefs, attitudes, and behaviors during the past 7 or 30 days. These time frames were chosen specifically: i) to incorporate a large enough time frame in order to facilitate meaningful variability from person to person, and ii) to minimize recall bias. Although the author cannot determine the exact extent to which recall bias affected the data, other researchers who have used similar measures have reported that recall bias is sufficiently minimal that its impact upon study findings is likely to be negligible. 58 This seems to be especially true when the recall period is small, as was the case for the main measures used in the present study. $.99,60$

Third, this study was based on cross-sectional data and is subject to limitations in attributions of causality as a result of this. No control group existed against which to compare the findings obtained in the present study. Likewise, as a result of having to rely upon cross-sectional data, the temporal ordering of some measures in terms of which variable(s) may be affecting which other(s) cannot be ascertained with scientific certainty. Future researchers wishing to test/replicate the findings obtained in the present study might want to consider implementing either a longitudinal or a prospective study design, to help remedy this particular limitation of The Bareback Project's data.

Also worth noting, the response/participation rate for The Bareback Project was relatively low $(\sim 10 \%)$, which could raise concern of selection bias and, therefore, the representativeness of the sample. Although it is difficult to be certain that the men who participated represent the men who did not, there is compelling evidence to suggest that differences between the two groups are minimal. Before The Bareback Project was started, the principal investigator conducted a large-scale content analysis with a random national sample of one of the main websites used by men to meet other men seeking unprotected sex partners.6163 The demographic composition of that sample and the one obtained in The Bareback Project closely match one another in terms of age representation, racial group composition, sexual orientation, and rural/suburban/urban location of residence. The two samples also resemble one another closely in terms of the types of sexual practices that men sought. The similarity of the two samples suggests that men who chose to participate in the present study represent those who did not, in terms of identifiable characteristics that are likely to be the best indicators of selection bias. Despite these similarities, the participation rate remains on the low side and thus represents a potential limitation for generalizability.

Despite these potential limitations, a number of interesting findings were revealed by this research. First, other than depression (which is discussed in greater detail below), mental health problems were relatively uncommon among the men participating in this study. This finding runs contrary to many scholars' expectations and to the research hypothesis that HIV risk taking is, for many MSM, a manifestation of mental health needs or problems. On the contrary, the present data suggest that these unprotected-sex-seeking men typically did not have poor self-images; the large majority of them had a good sense of self-esteem. Moreover, they were not dissatisfied with their current lives nor pessimistic about what their futures held in store for them. Rather, most of them expressed the viewpoint that their lives were fairly good and they anticipated good things for themselves in the future. Additionally, impulsivity was not characteristic of the large majority of these unprotected-sex-seeking men. Taken together, then, these data suggest that, for the most part, explanations other than being mentally unhealthy or psychologically needy account for why MSM such as those who took part in The Bareback Project sought out and engaged in the high rates of risky behaviors that typified their sex lives and drug use practices.

This conclusion is supported even further by the present study's findings regarding the rela- tionship of mental health functioning and involvement in HIV risk practices. In the substantial majority of the instances investigated, mental health functioning was not related to HIV risk taking. This was true for self-esteem, depression, impulsivity, current life satisfaction, and optimism about the future alike, for the prediction of almost all of the sexual and drug risk measures under study. Exceptions were noted for the number of drug problems experienced during the month prior to interview, which was related inversely to mental health functioning, and the number of sex partners men had during the month prior to interview, which was related to positive mental health functioning. Thus, this study's findings are more consistent with those reported by McCoul and Haslam, ${ }^{42}$ Reilly and Woo, ${ }^{24}$ and Safren and colleagues, ${ }^{27}$ whose studies did not find an association between mental health functioning and involvement in risky practices in their research populations than they are with those of the numerous other researchers whose work was cited earlier, in which HIV risk was related inversely to mental health functioning. In the present study of men who actively seek unprotected sex online, the extent of involvement in HIV risk practices was, in large part, attributable to factors other than self-esteem, depression, impulsivity, life satisfaction, and optimism about the future.

This is not to say, however, that mental health functioning is irrelevant to understanding these men's risk practices. In a separate work, the present author provided evidence to suggest that, in this study population, ${ }^{64}$ mental health functioning is related to risk practices, but that has its effects on HIV risk taking indirectly, principally through its impact upon attitudes toward condom use. The usually-hypothesized relationship of mental health $\rightarrow H I V$ risk practices appears to be too simplistic; rather, it appears that it would be more appropriate to characterize it as mental health $\rightarrow$ attitudes toward using condoms $\rightarrow$ HIV risk involvement. [Readers who are interested in learning more about the role that attitudes toward condom use seem to play in the overall understanding of risk practices among MSM in this population may wish to consult other articles published by the present author based on findings from The Bareback Project (see, for example, Klein 2011 and Klein \& Kaplan 2012)].65,66 These other works demonstrate the role that mental health variables play and how these measures interrelate with attitudes toward using condoms.

Additional research is needed to determine just how mental health problems, and mental illness operate when it comes to affecting HIV risk-related decision-making. Increasingly, research is showing that HIV risk practices are the result of complex webs of behavioral influences and numerous interacting factors. ${ }^{16,67}$ 
Increasingly scholars have been turning to theoretical models such as Syndemics Theory to try to account for the complicated ways in which the multitude of factors that affect HIV risk taking seem to be operating. ${ }^{68-70}$ Mental health factors are merely one of the many types of factors influencing men's risk practices.

Another important finding coming out of the present research is that a large proportion of the men $(27.6 \%)$ recently reported experiencing enough depressive symptoms so as to indicate the likely presence of clinical depression. This $27.6 \%$ figure is much greater than the $5.3 \%$ annual depression prevalence figure cited for adult men in the population-at-large (Substance Abuse Mental Health Services Administration, 2008). ${ }^{71}$ It is also either comparable to or greater than the prevalence figures reported by other researchers who have examined the prevalence of depression among various populations of MSM. For example, based on their population-based research with people residing throughout the state of California, Cochran and Mays found that 15.8\% of the MSM in their sample met the criteria for major depression, compared to $8.7 \%$ of their heterosexual male study participants. ${ }^{72}$ In a separate study conducted with a nationallyrepresentative population of adults aged 25 to 74 , Cochran, Sullivan, and Mays found that gay and bisexual men were approximately three times more likely than their heterosexual counterparts to report major depression at some point during the year prior to interview (31.0\% versus $10.2 \%) .{ }^{73}$ Hirshfield et al. ${ }^{74}$ conducted an anonymous online survey with Canadian and American MSM and found that $18 \%$ of these individuals met the diagnostic criteria for depression. A comparable figure (17.2\%) was obtained by Mills and colleagues based on their probability sample of MSM residing in any of four large urban cities in the United States. ${ }^{75}$ In their study of New York City-area men who used the Internet specifically to find partners for unprotected anal intercourse, Houston and colleagues found that $30 \%$ of their study participants scored either in the moderate or high range for depressive symptoms. ${ }^{76}$ This study is particularly noteworthy because its research population is similar to that comprising The Bareback Project, with the exception of the more-narrow geographic catchment area in Houston et al.'s study compared to that used for The Bareback Project.

Additional research is needed to understand the causes of depression among risk-taking, risk-seeking MSM, so that informed intervention efforts and courses of treatment can be developed and implemented. Moreover, additional research is needed to learn more about how depression affects these men's health behaviors. In the present study, despite being highly prevalent, depression was not found to predict the extent to which men engaged in practices that could lead them to acquire or transmit HIV. This stands in contradiction to the large majority of published studies (cited earlier), which have shown a link between greater depression and greater involvement in risky behaviors.

This begs an important, and currently unanswerable, question: why is it that depressed men in the present study were not more involved in risky behaviors than their nondepressed counterparts? It is possible that depression simply is not as salient or as immediate a factor in these men's sex lives and drug-use behaviors as other situational factors, such as partner preferences for sexual safety (or the lack thereof), partner preferences for drug use in conjunction with sexual relations, general discomfort discussing safer sex or negotiating for lowered-risk practices, and so forth. These latter influences have been shown by other researchers to be highly relevant to men's risk involvement, ${ }^{77,78}$ and their influence may be superseding that of depression in terms of affecting men's HIV-related decision-making. More research is needed to understand just how depression is and is not influential in this process, and the specific role that it plays in fostering risk behavior involvement among men who use the Internet to find partners for unprotected sex (as well as MSM more generally).

\section{References}

1. Centers for Disease Control and Prevention. HIV surveillance report, 2009. Available from: http://www.cdc.gov/hiv/surveillance/resources/reports/2009report/pdf /2009SurveillanceReport.pdf

2. Centers for Disease Control and Prevention. HIV/AIDS surveillance report, 2001. Available from: http://www.cdc.gov/ hiv/surveillance/resources/reports/2001rep ort_no2/. Accessed on: April 2013.

3. Adam BD. Constructing the neoliberal sexual actor: Responsibility and care of the self in the discourse of barebackers. Cult Health Sex 2005;7:333-46.

4. Carballo-Dieguez A, Bauermeister J. Barebacking: intentional condomless anal sex in HIV-risk contexts. Reasons for and against it. J Homosex 2004;47:1-16.

5. Halkitis PN, Green KA, Wilton L. Masculinity, body image, and sexual behavior in HIV-seropositive gay men: a two-phase formative behavioral investigation using the Internet. Int J Men Health 2004;3:27-42.

6. Halkitis PN, Parsons JT. Intentional unsafe sex (barebacking) among HIV-positive gay men who seek sexual partners on the Internet. AIDS Care 2003;15:367-78.

7. Ridge DT. It was an incredible thrill: the social meanings and dynamics of younger gay men's experiences of barebacking in Melbourne. Sexualities 2004;7:259-79.

8. Halkitis PN, Parsons JT, Wilton L. Barebacking among gay and bisexual men in New York City: explanations for the emergence of intentional unsafe behavior. Arch Sex Behav 2003;32:351-7.

9. Sheon N, Crosby GM. Ambivalent tales of HIV disclosure in San Francisco. Soc Sci Med 2004;58:2105-18.

10. Dilley JW, McFarland W, Woods WJ, et al. Thoughts associated with unprotected anal intercourse among men at high risk in San Francisco 1997-1999. Psychol Health 2002;17:235-46.

11. Mansergh G, Marks G, Colfax GN, et al. Barebacking in a diverse sample of men who have sex with men. AIDS 2002;16:6539.

12. Theodore PS, Duran REF, Antoni MH, Fernandez MI. Intimacy and sexual behavior among HIV-positive men who have sex with men in primary relationships. AIDS Behav 2004;8:321-31.

13. Adam BD, Husbands W, Murray J, Maxwell J. AIDS optimism, condom fatigue, or selfesteem: explaining unsafe sex among gay and bisexual men. J Sex Res 2005;32:23848.

14. Preston DB, D'Augelli AR, Kassab CD, Starks MT. The relationships of stigma to the sexual risk behavior of rural men who have sex with men. AIDS Educ Prev 2007;19:218-30.

15. Moskowitz DA, Seal DW. Self-esteem in HIV-positive and HIV-negative gay and bisexual men: implications for risk-taking behaviors with casual sex partners. AIDS Behav 2011;15:621-5.

16. Rosario M, Schrimshaw EW, Hunter J. A model of sexual risk behaviors among young gay and bisexual men: longitudinal associations of mental health, substance abuse, sexual abuse, and the coming-out process. AIDS Educ Prev 2006;18:444-60.

17. Stein JA, Rotheram-Borus MJ, Swendeman D, Milburn NG. Predictors of sexual transmission risk behaviors among HIV-positive young men. AIDS Care 2005;17:433-42.

18. Semple SJ, Patterson TL, Grant I. Psychosocial predictors of unprotected anal intercourse in a sample of HIV positive gay men who volunteer for sexual risk reduction intervention. AIDS Educ Prev 2000;12:416-30.

19. Semple SJ, Zians J, Grant I, Patterson TL. Methamphetamine use, impulsivity, and sexual risk behavior among HIV-positive men who have sex with men. J Addict Dis 
2006;25:105-14.

20. Grov C, Bimbi DS, Nanin JE, Parsons JT. Exploring racial and ethnic differences in recreational drug use among gay and bisexual men in New York City and Los Angeles. J Drug Educ 2006;36:105-23.

21. Halkitis PN, Jerome RC. A comparative analysis of methamphetamine use: black gay and bisexual men in relation to men of other races. Addict Behav 2008;33:83-93.

22. Nanin J, Fontaine YM, Wallace BC. Recommendations for researchers and clinicians working at the intersection of the HIV/AIDS and methamphetamine epidemics with MSM. In: Wallace BC, ed. Toward equity in health: a new global approach to health disparities. New York: Springer Publishing; 2008. pp 393-411.

23. Purcell DW, Moss S, Remien RH, et al. Illicit substance use, sexual risk, and HIVpositive gay and bisexual men: differences by serostatus of casual partners. AIDS 2005;19:s37-s47.

24. Reilly T, Woo G. Predictors of high-risk sexual behavior among people living with HIV/AIDS. AIDS Behav 2001;5:205-17.

25. Parsons JT, Halkitis PN. Sexual and drugusing practices of HIV-positive men who frequent public and commercial sex environments. AIDS Care 2002;14:815-26.

26. Shernoff M. Condomless sex: considerations for psychotherapy with individual gay men and male couples having unsafe sex. J Gay Lesb Ment Health 2005;9:149-69.

27. Safren SA, Traeger L, Skeer MR, et al. Testing a social-cognitive model of HIV transmission risk behaviors in HIV-infected MSM with and without depression. Health Psychol 2010;29:215-21.

28. Mimiaga MJ, Reisner SL, Fontaine YM, et al. Walking the line: stimulant use during sex and HIV risk behavior among Black urban MSM. Drug Alcohol Depend 2010;110:30-7.

29. Reisner SL, Mimiaga MJ, Skeer M, et al. Beyond anal sex: sexual practices associated with HIV risk reduction among men who have sex with men in Boston, Massachusetts. AIDS Patient Care STDS 2009;23:545-50.

30. Reisner SL, Mimiaga MJ, Skeer M, et al. Clinically significant depressive symptoms as a risk factor for HIV infection among Black MSM in Massachusetts. AIDS Behav 2009:13:798-810.

31. Salomon EA, Mimiaga MJ, Husnik MJ, et al. Depressive symptoms, utilization of mental health care, substance use and sexual risk among young men who have sex with men in EXPLORE: implications for age-specific interventions. AIDS Behav 2009;13:811-21.

32. Perdue T, Hagan H, Thiede H, Valleroy L. Depression and HIV risk behavior among
Seattle-area injection drug users and young men who have sex with men. AIDS Educ Prev 2003;15:81-92.

33. Murray J, Adam BD. Aging, sexuality, and HIV issues among older gay men. Canad $\mathrm{J}$ Hum Sex 2001;10:75-90.

34. Mimiaga MJ, Noonan E, Donnell D, et al. Childhood sexual abuse is highly associated with HIV risk-taking behavior and infection among MSM in the EXPLORE study. J Acq Immun Def Synd 2009;51:3408.

35. Parsons JT, Halkitis PN, Wolitski RJ, Gomez CA. Correlates of sexual risk behaviors among HIV-positive men who have sex with men. AIDS Educ Prev 2003;15:383-400.

36. Bousman CA, Cherner M, Ake C. et al. Negative mood and sexual behavior among non-monogamous men who have sex with men in the context of methamphetamine and HIV. J Affect Disord 2009;119:84-91.

37. Bancroft J, Janssen E, Strong D, et al. Sexual risk-taking in gay men: the relevance of sexual arousability, mood, and sensation seeking. Arch Sex Behav 2003;32:555-72.

38. Alvy LM, McKirnan DJ, Mansergh G, et al. Depression is associated with sexual risk among men who have sex with men, but is mediated by cognitive escape and self-efficacy. AIDS Behav 2011;15:1171-9.

39. Walch SE, Rudolph SE. Negative affect and risk for human immunodeficiency virus: one size may not fit all. Am J Health Promot 2006;20:324-33.

40. Semple SJ, Zians J, Grant I, Patterson TL. Sexual compulsivity in a sample of HIVpositive methamphetamine-using gay and bisexual men. AIDS Behav 2006;10:587-98.

41. Dudley MG, Rostosky SS, Korfhage BA, Zimmerman RS. Correlates of high-risk sexual behavior among young men who have sex with men. AIDS Educ Prev 2004;16:328-40.

42. McCoul MA, Haslam N. Predicting high risk sexual behavior in heterosexual and homosexual men: the roles of impulsivity and sensation seeking. Pers Indiv Differ 2001;31:1303-10.

43. Yi H, Sandfort TGM, Shidlo A. Effects of disengagement coping with HIV risk on unprotected sex among HIV-negative gay men in New York City. Health Psychol 2010;29:205-14.

44. Kelly BC, Bimbi DS, Izienicki H, Parsons JT. Stress and coping among HIV-positive barebackers. AIDS Behav 2009;13:792-7.

45. Martin JI, Pryce JG, Leeper JD. Avoidance coping and HIV risk behavior among gay men. Health Soc Work 2005;30:193-201.

46. Morin SF, Steward WT, Charlebois ED, et al. Predicting HIV transmission risk among HIV-infected men who have sex with men: findings from the healthy living project. J Acquir Immune Defic Syndr 2005;40:226-35.

47. Rosenberg M. Society and the adolescent self-image. Princeton: Princeton University Press; 1965.

48. Radloff LS. The CES-D scale: a self-report depression scale for research in the general population. Appl Psych Meas 1977;1:385401.

49. Turley CL, Wallace RB, Herzog R. A revised CES-D measure of depressive symptoms and a DSM-based measure of major depressive episodes in the elderly. Int Psychogeriatr 1999;11:139-48.

50. Van Dam NT, Earleywine M. Validation of the center for epidemiologic studies depression scale-revised (CESD-R): pragmatic depression assessment in the general population. Psych Res 2011;186:128-32.

51. Von Diemen L, Szobot CM, Kessler F, Pechansky F. Adaptation and construction of the Barratt impulsiveness scale BIS 11 to Brazilian Portuguese for use in adolescents. Rev Bras Psiquiatr 2007;29:153-6.

52. Diener E, Emmons RA, Larsen RJ, Griffin S. The satisfaction with life scale. J Pers Assess 1985;49:71-5.

53. Scheier MF, Carver CS. Optimism, coping, and health: assessment and implications of generalized outcome expectancies. Health Psychol 1985;4:219-47.

54. Mulhauser G. Welcome to the center for epidemiologic studies depression scale (CES-D), a screening test for depression. Available from: http://counsellingresource.com/lib/quizzes/depression-testing/cesd. Accessed on: April 2013.

55. Schrimshaw EW, Rosario M, MeyerBahlburg HFL, Scharf-Matlick AA. Testretest reliability of self-reported sexual behavior, sexual orientation, and psychosexual milestones among gay, lesbian, and bisexual youths. Arch Sexual Behav 2006;35:225-34.

56. Bogart LM, Walt LC, Pavlovic JD, et al. Cognitive strategies affecting recall of sexual behavior among high-risk men and women. Health Psychol 2007;26:787-93.

57. Morisky DE, Ang A, Sneed CD. Validating the effects of social desirability on selfreported condom use behavior among commercial sex workers. AIDS Educ Prev 2002;14:351-60.

58. Kauth MR, St Lawrence JS, Kelly JA. Reliability of retrospective assessments of sexual HIV risk behavior: a comparison of biweekly, three-month, and twelve-month self-reports. AIDS Educ Prev 1991;3:20714.

59. Fenton KA, Johnson AM, McManus S, Erens B. Measuring sexual behaviour: methodological challenges in survey 
research. Sex Transm Infect 2001;77, 8492.

60. Weir SS, Roddy RE, Zekeng L, Ryan KA. Association between condom use and HIV infection: a randomised study of self reported condom use measures. J Epidemiol Commun Health 1999;53:41722.

61. Klein H. HIV risk practices sought by men who have sex with other men, and who use Internet websites to identify potential sexual partners. Sex Health 2008;5:243-50.

62 . Klein H. Sexual orientation, drug use preference during sex, and HIV risk practices and preferences among men who specifically seek unprotected sex partners via the Internet. Int J Environ Res Public Health 2009;6:1620-35.

63. Klein H. Differences in HIV risk practices sought by self-identified gay and bisexual men who use Internet websites to identify potential sexual partners. J Bisex 2009;9:125-40.

64. Klein H, Tilley DL. Childhood maltreatment and HIV risk taking among men using the Internet specifically to find partners for unprotected sex. Int Publ Health J 2012;4:33-42.

65. Klein $H$. Using a syndemics theory approach to study HIV risk taking in a population of men who use the Internet to find partners for unprotected sex. Am J of Men Health 2011;5:466-76.

66. Klein H, Kaplan RL. Condom use attitudes and HIV risk taking among American MSM seeking partners for unprotected sex via the Internet. Int Publ Health J 2012;4:419-
34.

67. Catania JA, Paul J, Osmond D, et al. Mediators of childhood sexual abuse and high-risk sex among men-who-have-sexwith-men. Child Abuse Neglect 2008;32, 925-40.

68. Mustanski B, Garofalo R, Herrick A, Donenberg G. Psychosocial health problems increase risk for HIV among urban young men who have sex with men: preliminary evidence of a syndemic in need of attention. Ann Behav Med 2007;34:37-45.

69. Stall R, Friedman M, Cantania JA. Interacting epidemics and gay men's health: a theory of syndemic production among urban gay men. In: Wolitski RJ, Stall R, Valdiserri R0, eds. Unequal opportunity: health disparities affecting gay and bisexual men in the United States. New York: Oxford University Press; 2008. pp. 251-274.

70. Stall R, Mills TC, Williamson J, et al. Association of co-occurring psychosocial health problems and increased vulnerability to HIV/AIDS among urban men who have sex with men. Am J Public Health 2003;93:939-42.

71. Substance Abuse Mental Health Services Administration. 2007 National Survey on Drug Use and Health: detailed tables. Rockville: Office of Applied Studies; 2008.

72. Cochran SD, Mays VM. Burden of psychiatric morbidity among lesbian, gay, and bisexual individuals in the California quality of life survey. J Abnorm Psychol 2009;118:647-58.

73. Cochran SD, Sullivan JG, Mays VM.
Prevalence of mental disorders, psychological distress, and mental health services use among lesbian, gay, and bisexual adults in the United States. J Consul Clin Psychol 2003;71:53-61.

74. Hirshfield S, Wolitski RJ, Chiasson MA, et al. Screening for depressive symptoms in an online sample of men who have sex with men. AIDS Care 2008;20:904-10.

75. Mills TC, Paul J, Stall R, et al. Distress and depression in men who have sex with men: the urban men's health study. Am J Psychiatr 2004;16:278-85.

76. Houston E, Sandfort T, Dolezal C, CarballoDieguez A. Depressive symptoms among MSM who engage in bareback sex: does mood matter? AIDS Behav 2012;16:220915.

77. Horvath KJ, Nygaard K, Rosser BRS. Ascertaining partner HIV status and its association with sexual risk behavior among Internet-using men who have sex with men. AIDS Behav 2010;14:1376-83.

78. Mansergh G, McKirnan DJ, Flores SA, et al. HIV-related attitudes and intentions for high-risk, substance-using men who have sex with men: associations and clinical implications for HIV-positive and HIV-negative MSM. J Cognitive Psychother 2010;24:281-93.

79. Ross MW, Rosser BRS, Neumaier ER. The relationship of internalized homonegativity to unsafe sexual behavior in HIV seropositive men who have sex with men. AIDS Educ Prev 2008;20:547-57. 6 